\title{
PENGARUH SISTEM OLAH TANAH DAN APLIKASI MULSA BAGAS TERHADAP BIOMASSA KARBON MIKROORGANISME TANAH (C-MIK) PADA LAHAN PERTANAMAN TEBU (Saccharum officinarum L.) TAHUN KE-5
}

\author{
Nur Mutiara Pauza, Ainin Niswati, Dermiyati \& Sri Yusnaini \\ Jurusan Agroteknologi, Fakultas Pertanian Universitas Lampung, \\ Jl. Prof. Soemantri Brodjonegoro, No. 1, Bandar Lampung 35145. \\ Email : nurmutiarapauza@yahoo.com
}

\begin{abstract}
ABSTRAK
Upaya yang dilakukan untuk memperbaiki kualitas lahan yang telah terdegradasi antara lain dengan penerapan sistem tanpa olah tanah (TOT) dan pemberian mulsa bagas. Penelitian ini bertujuan untuk Penelitian ini bertujuan untuk mengetahui pengaruh olah tanah dan aplikasi mulsa bagas terhadap biomassa karbon mikroorganisme tanah (C-mik). Penelitian ini dilakukan dengan menggunakan rancangan petak terbagi dan disusun secara split plot dengan 5 ulangan. Sebagai petak utama adalah perlakuan sistem olah tanah $(\mathrm{T})$ yaitu: $\mathrm{T}_{0}=\operatorname{tanpa}$ olah tanah; $\mathrm{T}_{1}=$ olah tanah intensif dan anak petak dalam penelitian ini adalah penggunaan limbah pabrik gula (M) yaitu: $\mathrm{M}_{0}=$ tanpa mulsa ; $\mathrm{M}_{1}=$ mulsa bagas 80 ton ha ${ }^{-1}$. Semua perlakuan diaplikasikan pupuk anorganik NPK, dan aplikasi bahan organik BBA $80 \mathrm{t} \mathrm{ha}^{-1}$. Data yang diperoleh diuji homogenitasnya dengan Uji Bartlet dan aditivitasnya dengan Uji Tukey, serta uji lanjut dengan Uji Beda Nyata Terkecil (BNT). Hasil penelitian menunjukkan bahwa, sistem olah tanah tidak berpengaruh terhadap C-mik tanah, pada perlakuan aplikasi mulsa bagas hasil C-mik tanah lebih tinggi dibandingkan dengan perlakuan tanpa mulsa bagas pada waktu pengamatan 0, 3 dan 9 BST dan tidak terdapat interkasi antara sistem olah tanah dan aplikasi mulsa bagas terhadap C-mik tanah. Terdapat korelasi antara $\mathrm{pH}$ tanah dan suhu tanah dengan $\mathrm{C}$-mik tanah, namun C-organik tanah dan kadar air tanah tidak berkorelasi nyata dengan C-mik tanah.
\end{abstract}

Kata kunci: c-mik, mulsa bagas, olah tanah intensif, tanpa olah tanah

\section{PENDAHULUAN}

Budidaya tanaman tebu yang diterapkan oleh PT GMP adalah dengan olah tanah secara intensif sejak berdirinya perusahaan ini pada tahun 1975. Namun sistem olah tanah intensif (OTI) yang dilakukan secara terus menerus mengakibatkan degradasi pada tanah seperti terjadinya pemadatan pada tanah, berkurangnya ketersediaan air tanah, semakin kurang berkembangnya sistem perakaran tanaman, penurunan kandungan bahan organik, kerusakan struktur dan agregat tanah (PT Gunung Madu Plantations, 2009).

Sistem tanpa olah tanah (TOT) dan aplikasi mulsa bagas hasil dari limbah pabrik gula dapat dijadikan sebagai alternatif dalam penyiapan lahan agar mampu mempertahankan produktivitas tanah tetap tinggi. Dalam sistem TOT, tanah dibiarkan saja dan tidak terganggu oleh adanya cangkulan atau bajakan pada bagian tanah. Mulsa yang dimanfaatkan di PT GMP yaitu mulsa bagas dan aplikasi pupuk organik berupa BBA. BBA merupakan limbah padat yang dihasilkan oleh pabrik gula di PT GMP.
Kandungan bahan organik dari pemberian mulsa bagas akan mempengaruhi kesuburan tanah. Mikroorganisme membutuhkan bahan organik sebagai sumber energi dalam pertumbuhannya. Bahan organik mempengaruhi pembentukan biomassa mikroorganisme. Menurut Jenkinson dan Ladd (1981) dalam Djajakirana (2003), biomassa mikroorganisme tanah (C-mik) merupakan bagian hidup dari bahan organik tanah di luar akar-akar tanaman dan fauna tanah.

Mikroorganisme tanah sangat berperan penting dalam proses-proses yang terjadi di tanah, seperti siklus karbon dan ketersediaan hara. Dalam perbaikan tanah, perlu diketahui kadar C-mik tanah. Penelitian ini bertujuan untuk mengetahui pengaruh sistem olah tanah dan aplikasi mulsa bagas terhadap biomassa karbon mikroorganisme tanah (C-mik) pada lahan pertanaman tebu (Saccharum officinarum L.) tahun ke-5.

\section{BAHAN DAN METODE}

Penelitian ini dilaksanakan di perkebunan tebu PT Gunung Madu Plantations (GMP) Kecamatan Gunung 
Batin Kabupaten Lampung Tengah dan secara geografis terletak oada garis lintang 4-40 ${ }^{\circ} \mathrm{LS}$ dan garis bujur 105$13{ }^{\circ} \mathrm{BT}$ dengan ketinggian $45 \mathrm{~m}$ dpl. Analisis biomassa mikroorganisme dan contoh tanah dilakukan di Laboratorium Ilmu Tanah, Jurusan Agroteknologi, Fakultas Pertanian, Universitas Lampung. Penelitian ini dilaksanakan pada bulan Oktober 2014 sampai Juni 2015.

Rancangan Percobaan yang digunakan dalam penelitian ini yaitu rancangan acak kelompok (RAK) yang disusun secara split plot dan diulang sebanyak 5 kali ulangan. Petak utama yaitu perlakuan sistem olah tanah yang berupa tanpa olah tanah $\left(\mathrm{T}_{0}\right)$ dan olah tanah intensif $\left(\mathrm{T}_{1}\right)$. Anak petak adalah pemberian mulsa bagas yaitu berupa lahan menggunkan mulsa bagas $\left(\mathrm{M}_{0}\right)$ dan lahan tanpa menggunakan mulsa bagas $\left(\mathrm{M}_{1}\right)$. Dari perlakuan-perlakuan ini maka akan didapatkan kombinasi 4 perlakuan.

Kombinasi perlakuan yang diterapkan adalah sebagai berikut :

$\mathrm{T}_{0} \mathrm{M}_{0}=$ tanpa olah tanah + tanpa mulsa bagas

$\mathrm{T}_{1} \mathrm{M}_{0}=$ olah tanah intensif + tanpa mulsa bagas

$\mathrm{T}_{0} \mathrm{M}_{1}=$ tanpa olah tanah + mulsa bagas 80 ton per hektar $\mathrm{T}_{1} \mathrm{M}_{1}=$ olah tanah intensif + mulsa bagas 80 ton per ha

Dari 4 kombinasi perlakuan di atas diulang sebanyak 5 kali. Data yang didapatkan dianalisis dengan sidik ragam yang sebelumnya diuji homogenitas ragamnya dengan uji Bartlet dan aditivitas data diuji dengan uji Tukey. Rata-rata nilai tengah perlakuan diuji dengan uji BNT pada taraf nyata 5\%.

Lahan pada petak percobaan dengan sistem olah tanah intensif tanah diolah dengan menggunakan sistem yang telah diterapkan di PT GMP, yaitu dengan pengolahan tanah sebanyak 3 kali. Aplikasi BBA sebagai mulsa dilakukan secara manual pada petak percobaan yang menggunakan perlakuan mulsa bagas dengan dosis 80 ton perhektar dan diberikan setelah penanaman tebu.

Pada petak percobaan dengan sistem tanpa olah tanah, tanah tidak diolah dan aplikasi bahan organik atau BBA hanya dilakukan dengan menebar pada permukaan atas lahan bersamaan pada aplikasi dipetak olah tanah intensif, selanjutnya aplikasi BBA sebagai mulsa dilakukan juga secara manual pada petak percobaan yang menggunakan perlakuan mulsa bagas dengan dosis yang sama yaitu 80 ton per hektar. Pada semua petak percobaan dan semua perlakuan diberikan pupuk kimia berupa pupuk urea dengan dosis $300 \mathrm{~kg}$ perhektar, pupuk TSP dengan dosis $200 \mathrm{~kg}$ perhektar dan pupuk MOP dengan dosis $300 \mathrm{~kg}$ per hektar.

Pengambilan contoh tanah dilakukan dengan menggukan bor tanah dan secara acak terstruktur dilokasi yang telah ditentukan. Contoh tanah diambil dengan menentukan titik-titik pengambilan secara melingkar dengan titik tengah plot sebagai pusatnya, didapatkan sebanyak 12 titik kemudian tanah diambil menggunakan bor tanah dengan kedalaman $20 \mathrm{~cm}$ dan kemudian dimasukkan ke dalam ember dan dikompositkan.

Pengamatan analisis C-Organik, kadar air tanah dan $\mathrm{pH}$ tanah dilakukan di Laboratorium Ilmu Tanah, Fakultas Pertanian, Universitas Lampung. Pada penelitian ini variabel utama pengamatannya adalah pengukuran C-mik tanah yang dilakukan dengan menggunakan metode fumigasi-inkubasi (Jenkinson dan Powlson, 1976) yang telah disempurnakan oleh Franzluebbers dkk., 1995). Proses pelaksanaan analisis yang dilakukan yaitu dengan cara menimbang $100 \mathrm{~g}$ tanah lembab dan ditempatkan dalam gelas beaker 50 ml. Kemudian tanah tersebut difumigasi dengan menggunakan kloroform $\left(\mathrm{CHCl}_{3}\right)$ sebanyak $30 \mathrm{ml}$ dalam desikator yang telah diberi tekanan $50 \mathrm{~cm} \mathrm{Hg}$ selama 48 jam dan setelah proses fumugasi selama 48 jam selesai, tanah dibebaskan dari dibawah tekanan $30 \mathrm{~cm}$ $\mathrm{Hg}$. Selanjutnya sebanyak $10 \mathrm{~g}$ tanah inokulan diikat rapat dalam plastik dan dimasukkan ke dalam lemari pendingin sampai proses fumigasi selesai. Setelah proses fumigasi selesai selama 48 jam, setiap contoh tanah dimasukkan ke dalam toples berukuran 1 liter dan tanah inokulan juga dikeluarkan dari lemari pendingin, sebelum dicampurkan bersamaan dengan tanah fumigasi, tanah inokulan tersebut didiamkan selama kurang lebih 30 menit (proses aklimatisasi), setelah tanah berada di dalam toples dua botol film juga dimasukkan secara bersamaan, satu botol berisi $10 \mathrm{ml} \mathrm{KOH} \mathrm{0,5} \mathrm{N}$ dan satu botol berisi $10 \mathrm{ml}$ aquades. selanjutnya toples tersebut ditutup sampai kedap udara dengan menggunakan lakban dan diinkubasi pada suhu $25^{\circ} \mathrm{C}$ ditempat gelap selama 10 hari.

Pada akhir inkubasi, ditambahkan indikator phenophtalein sebanyak 2 tetes pada beaker berisi $\mathrm{KOH}$ dan dititrasi dengan $\mathrm{HCl} 0,1 N$ hingga warna merah hilang. Jumlah $\mathrm{HCl}$ yang ditambahkan dicatat, selanjutnya ditambahkan 2 tetes metil orange dan dititrasi dengan $\mathrm{HCl}$ hingga warna kuning berubah menjadi merah muda. Sedangkan untuk tanah nonfumigasi digunakan dengan $100 \mathrm{~g}$ tanah berat kering oven. Kemudian tanah tersebut dimasukkan ke dalam toples berukuran 1 liter beserta $10 \mathrm{ml} 0,5 \mathrm{~N} \mathrm{KOH}$ dan satu botol film berisi $10 \mathrm{ml}$ aquades tanpa penambahan tanah inokulan. Variabel pendukung yang diamati dan dianalisis yaitu Kadar C-organik, pH tanah, Suhu tanah dan Kadar air tanah. 


\section{HASIL DAN PEMBAHASAN}

Hasil pengamatan C-mik pada pengambilan sampel 0, 3, 6 dan 9 bulan setelah tanam (BST) dapat dilihat pada Tabel 1. Hasil analisis ragam dan ringkasannya menunjukkan bahwa perlakuan sistem olah tanah tidak berpengaruh nyata terhadap C-mik tanah, tetapi pemberian mulsa bagas berpengaruh nyata terhadap C-mik tanah tahun ke-5 pada 0, 3, dan 9 BST, namun tidak berpengaruh nyata pada 6 BST.

Hasil menunjukkan bahwa perlakuan olah tanah dan aplikasi mulsa bagas tidak memiliki interaksi (Tabel 1). Hasil uji BNT pada taraf 5\%, (Tabel 2) menunjukkan
C-mik tanah dengan perlakuan aplikasi mulsa bagas lebih tinggi dibandingkan perlakuan tanpa mulsa bagas pada 0 dan 3 BST, namun pada 9 BST C-mik tanah dengan perlakuan tanpa mulsa bagas lebih tinggi dibandingkan dengan perlakuan aplikasi mulsa bagas. Gambar 1 menunjukkan nilai C-mik tanah dengan perlakuan sistem olah tanah dan aplikasi mulsa bagas masih mengalami fluktuasi.

Berdasarkan data penelitian analisis kimia tanah menunjukkan hasil C-Organik tanah pada lahan penelitian memiliki kandungan yang rendah. Selanjutnya pada $\mathrm{pH}$ tanah juga mengalami hal yang sama. Pada lahan penelitian ini $\mathrm{pH}$ tanah tergolong masam dan tidak

Tabel 1. Perlakuan sistem olah tanah dan aplikasi mulsa bagas terhadap perubahan C-mik tanah dan F-hitung selama pertanaman tebu (Plant cane) tahun kelima.

\begin{tabular}{|c|c|c|c|c|c|c|}
\hline Perlakuan & $0 \mathrm{BST}$ & & $3 \mathrm{BST}$ & $6 \mathrm{BST}$ & & $9 \mathrm{BST}$ \\
\hline \multicolumn{7}{|c|}{$\mathrm{mg} \mathrm{CO}_{2}-\mathrm{C} \mathrm{kg} \mathrm{tanah}{ }^{-1}$ hari $^{-1}$} \\
\hline $\mathrm{T}_{0} \mathrm{M}_{0}$ & 87,92 & $\pm 25,20$ & $118,36 \pm 25,62$ & 177,36 & $\pm 44,97$ & $279,26 \pm 66,83$ \\
\hline $\mathrm{T}_{0} \mathrm{M}_{1}$ & 177,38 & $\pm 91,57$ & $121,00 \pm 45,04$ & 218,98 & $\pm 63,67$ & $197,32 \pm 73,54$ \\
\hline $\mathrm{T}_{1} \mathrm{M}_{0}$ & 176,02 & $\pm 75,38$ & $124,22 \pm 35,14$ & 215,32 & $\pm 48,70$ & $264,78 \pm 31,62$ \\
\hline $\mathrm{T}_{1} \mathrm{M}_{1}$ & 212,48 & $\pm 49,90$ & $165,86 \pm 46,16$ & 239,70 & $\pm 123,02$ & $197,70 \pm 49,72$ \\
\hline \multicolumn{3}{|c|}{ Sumber Keragaman } & \multicolumn{4}{|c|}{ F-hitung dan Signifikasi } \\
\hline Sistem Ola & $\mathrm{ah}(\mathrm{T})$ & $1,80^{\operatorname{tn}}$ & $0,72^{\text {tn }}$ & & $4,51^{\text {tn }}$ & $1,83^{\text {tn }}$ \\
\hline Aplikasi M & (M) & $8,27^{*}$ & $5,46^{*}$ & & $0,77^{\text {tn }}$ & $5,60^{*}$ \\
\hline Interaksi ( & & $1,47^{\mathrm{tn}}$ & $4,24^{\mathrm{tn}}$ & & $0,05^{\mathrm{tn}}$ & $0,06^{\mathrm{tn}}$ \\
\hline
\end{tabular}

Keterangan: $\mathrm{T}_{0}=$ Tanpa olah tanah; $\mathrm{T}_{1}=$ Olah tanah intensif; $\mathrm{M}_{0}=$ Tanpa mulsa; $\mathrm{M}_{1}=$ Aplikasi mulsa bagas; $\mathrm{tn}=$ Tidak berbeda nyata; $*$ = nyata pada taraf $5 \%$.

Tabel 2. Pengaruh perlakuan sistem olah tanah dan aplikasi mulsa bagas terhadap C-mik tanah selama pertanaman tebu (Plant cane) tahun kelima.

\begin{tabular}{llll}
\hline \multirow{2}{*}{ Perlakuan } & \multicolumn{3}{l}{ C-mik tanah $\left(\mathrm{mg} \mathrm{CO}_{2}-\mathrm{C} \mathrm{kg} \mathrm{tanah}{ }^{-1}\right.$ hari $\left.^{-1}\right)$} \\
\cline { 2 - 4 } & 0 BST & 3 BST & 9 BST \\
\hline $\mathrm{M}_{0}$ (Tanpa mulsa bagas) & $131,97 \mathrm{a}$ & $121,29 \mathrm{a}$ & $272,02 \mathrm{~b}$ \\
$\mathrm{M}_{1}$ (Aplikasi mulsa bagas) & $194,93 \mathrm{~b}$ & $143,43 \mathrm{~b}$ & $197,51 \mathrm{a}$ \\
\hline BNT $_{0,05}$ & 50,48 & 21,83 & 72,60 \\
\hline
\end{tabular}

Keterangan: Nilai tengah yang diikuti huruf yang sama pada kolom yang sama tidak berbeda nyata berdasarkan uji BNT pada taraf $5 \%$.

Tabel 3. Pengaruh sistem olah tanah dan aplikasi mulsa bagas pada pertanaman tebu (Plant cane) tahun kelima terhadap beberapa sifat kimia tanah.

\begin{tabular}{llllrrr}
\hline \multirow{2}{*}{ Perlakuan } & $\begin{array}{l}\text { C-Organik } \\
(\%)\end{array}$ & $\begin{array}{l}\mathrm{pH} \text { tanah } \\
\left(\mathrm{H}_{2} \mathrm{O}\right)\end{array}$ & \multicolumn{2}{l}{$\begin{array}{l}\text { Kadar Air Tanah } \\
(\%)\end{array}$} & \multicolumn{3}{l}{$\begin{array}{l}\text { Suhu Tanah } \\
\left({ }^{\circ} \mathrm{C}\right)\end{array}$} \\
\cline { 2 - 7 } & $3 \mathrm{BST}$ & $3 \mathrm{BST}$ & $3 \mathrm{BST}$ & $6 \mathrm{BST}$ & $3 \mathrm{BST}$ & 6 BST \\
\hline $\mathrm{T}_{0} \mathrm{M}_{0}$ & 1,45 & 5,32 & 22,74 & 24,03 & 31,40 & 27,40 \\
$\mathrm{~T}_{0} \mathrm{M}_{1}$ & 1,34 & 5,34 & 22,30 & 25,03 & 30,40 & 27,80 \\
$\mathrm{~T}_{1} \mathrm{M}_{0}$ & 1,28 & 5,27 & 18,41 & 21,74 & 30,20 & 27,20 \\
$\mathrm{~T}_{1} \mathrm{M}_{1}$ & 1,22 & 5,23 & 20,51 & 22,60 & 30,40 & 27,20 \\
\hline
\end{tabular}

Keterangan: $\mathrm{T}_{1}=$ olah tanah; $\mathrm{T}_{0}=$ tanpa olah tanah; $\mathrm{M}_{1}=$ aplikasi mulsa bagas; $\mathrm{M}_{0}=$ tanpa aplikasi mulsa bagas. 


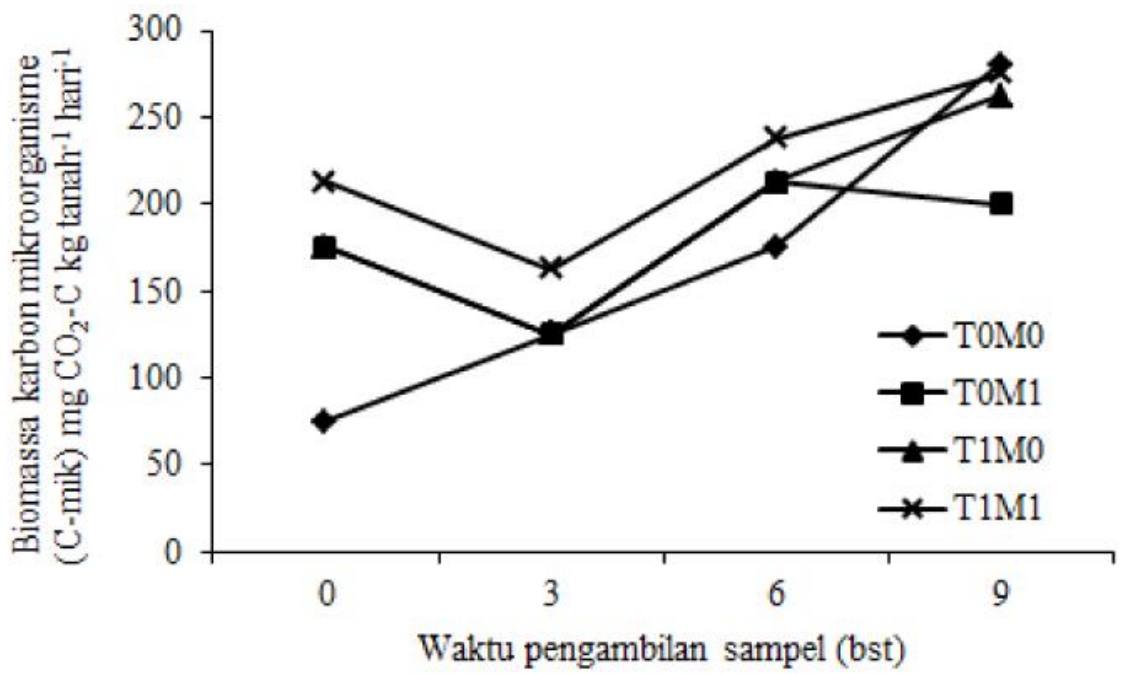

Gambar 1. Dinamika perkembangan C-mik tanah dengan perlakuan sistem olah tanah dan aplikasi mulsa bagas

memiliki perbedaan dari perlakuan sistem olah tanah maupun aplikasi mulsa bagas. Kemudian kadar air tanah meningkatan dari 3 hingga 6 BST. Selanjutnya pada suhu tanah pengamatan dari 3 hingga 6 BST mengalami penurnan. Berdasarkan hasil uji korelasi (Tabel 4), $\mathrm{pH}$ tanah dan suhu tanah berkorelasi nyata dengan C-mik tanah, namun C-organik tanah dan kadar air tanah tidak berkorelasi nyata dengan C-mik tanah.

Hasil penelitian menunjukkan bahwa perlakuan sistem olah tanah tidak berpengaruh nyata terhadap Cmik tanah, namun perlakuan aplikasi mulsa bagas memberikan pengaruh nyata terhadap C-mik tanah. Hal ini diduga karena mulsa bagas merupakan bahan organik yang mampu meningkatkan keberadaan mikroorganisme. Hal ini karena mikroorganisme membutuhkan bahan organik sebagai sumber energi dan juga berperan dalam proses dekomposisi.

Pada penelitian ini kedua jenis perlakuan olah tanah yang diterapkan tidak memberikan pengaruh yang nyata terhadap nilai C-mik tanah. Hal ini diduga karena OTI yang telah dilakukan selama 35 tahun oleh PT GMP mengakibatkan terjadinya degradasi tanah seperti pemadatan tanah. Waktu penelitian yang baru dilakukan selama 5 tahun dan penerapan perlakuan TOT yang baru diterapkan sebanyak 2 kali merupakan salah satu alasan sistem olah tanah tidak memberikan hasil yang nyata bagi C-mik tanah. Sehingga perbaikan kualitas tanah yang telah terdegradasi akibat OTI belum terlihat. Hal ini didukung oleh Utomo (2012) dalam penelitian teknologi penerapan TOT yang telah dilakukan sejak tahun 1987, bahwa pengamatan ke-10 TOT pada tahun ke-5 menunjukkan adanya kemantapan agregat dan ketahanan bongkahan rata-rata dua kali lebih tinggi daripada sistem OTI. Penelitian teknologi penerapan
TOT telah melakukan perlakuan penerapan TOT di lahan penelitian sejak awal dan berbeda dengan penelitian ini yang awalnya melakuan OTI sehingga belum mampu memperbaiki kerusakan tanah.

Hasil pengamatan (Gambar 1) perlakuan $\mathrm{T}_{0} \mathrm{M}_{0}$ menunjukkan C-mik tanah terus meningkat pada waktu pengamatan 0 hingga $9 \mathrm{BST}$, berbeda dengan perlakuan $\mathrm{T}_{0} \mathrm{M}_{1}, \mathrm{~T}_{1} \mathrm{M}_{0}$ dan $\mathrm{T}_{1} \mathrm{M}_{1}$ dimana $\mathrm{C}$-mik tanah pada waktu pengamatan 0 hingga 9 BST mengalami peningkatan dan penurunan. Hal tersebut diduga karena pertumbuhan mikroorganisme dipengaruhi oleh sisklus hidupnya. Pada awal pengamatan lahan penelitian baru saja diaplikasikan pupuk organik dan anorganik sehingga jumlah mikroorganisme akan meningkat. Kemudian nilai C-mik tanah menurun dikarenakan substrat nutrisi yang dibutuhkan oleh mikroorganisme sebagai sumber energi mulai habis. Sehingga terjadi perebutan makanan antar mikroorganisme dan mengakibatkan jumlah mikroorganisme tanah akan menurun.

Perlakuan sistem TOT memberikan keadaan lingkungan yang lebih baik bagi mikroorganisme tanah dibandingkan dengan sistem OTI. Perlakuan $\mathrm{T}_{0} \mathrm{M}_{0}$ keberadaan mikroorganisme lebih banyak dikarenakan perlakuan ini tanah tidak diolah dan bahan organik yang diberikan pada lahan hanya berada di atas permukaan sehingga keberadaan mikroorganisme lebih meningkat dibandingkan dengan tanah yang diolah dan bahan organik dicampurkan ke dalam tanah dan menyebabkan bahan organik akan terpendam. Hal ini sejalan dengan penelitian Beauchamp dan Hume (1997) dalam Margarettha (2004), menyatakan bahwa aktivitas mikroba pada TOT kedalaman 0-5 $\mathrm{cm}$ lebih tinggi dibandingkan dengan aktifitas mikroba pada olah tanah konvensional. Hal ini sebabkan karena pengolahan tanah 
Tabel 4. Ringkasan uji korelasi antara C-mik tanah dengan C-organik tanah dan $\mathrm{pH}$ tanah pada saat tanaman tebu 3 BST tahun kelima serta suhu tanah dan kadar air tanah pada saat tanaman tebu 3 BST dan 6 BST tahun kelima.

\begin{tabular}{lll}
\hline & \multicolumn{1}{c}{ Variabel } & \multicolumn{1}{c}{$\begin{array}{c}\text { Koefisien } \\
\text { Korelasi ( r ) }\end{array}$} \\
\hline 3 BST & C-Organik $^{1)}$ & $-0,18^{\text {tn }}$ \\
& pH tanah $^{1)}$ & $-0,48^{*}$ \\
3 dan 6 BST & & \\
& Kadar Air $^{2)}$ & $0,18^{\text {tn }}$ \\
& Suhu tanah $^{2)}$ & $-0,33^{*}$ \\
\hline
\end{tabular}

Keterangan: $\mathrm{tn}=$ tidak nyata; $*=$ nyata pada taraf $5 \%$; $* *$ = nyata pada taraf $1 \% ;{ }^{1)}=\mathrm{n}=10 ;{ }^{2)}=$ $\mathrm{n}=40$.

berpengaruh terhadap perombakan sisa tanaman, aktivitas akar dan kisaran kelembaban tanah yang pada akhirnya berpengaruh terhadap aktivitas mikroba di dalam tanah.

Selanjutnya selain karena pengaruh sistem TOT pada perlakuan $\mathrm{T}_{0} \mathrm{M}_{0}$ tanah tidak diberikan mulsa bagas dan hanya ada pemberian bahan organik yang berupa BBA. Sehingga mikrorganisme tanah akan langsung memanfaatkan bahan organik tersebut untuk sumber energinya, mikroorganisme lebih mudah merombak bahan organik ini karena BBA memiliki $\mathrm{C} / \mathrm{N}$ ratio yang lebih rendah $(<30)$ dibandingkan dengan mulsa bagas (86) yang sulit terdekomposisi.

Berdasarkan data hasil pengamatan perlakuan apliksai mulsa bagas $\left(\mathrm{M}_{1}\right)$ menunjukkan keadaan yang sama (Gambar 1). Pengamatan 9 BST menunjukkan nilai C-mik tanah menurun pada perlakuan dengan aplikasi mulsa $\left(\mathrm{M}_{1}\right)$. Hal tersebut karena mulsa bagas sebagai bahan organik memiliki kualitas yang rendah dengan nisbah $\mathrm{C} / \mathrm{N}$ yang tinggi (86) dan kandungan hara yang rendah $(0,3 \% \mathrm{~N}, 0,34 \% \mathrm{P}, 0,14 \% \mathrm{~K}, 42,5 \% \mathrm{C})$ (Pratiwi, 2013). Selain itu, mulsa merupakan suatu upaya yang dilakukan untuk memperbaiki keadaan lingkungan tanah, dari adanya lingkungan tanah yang baik maka akan semakin mendukung kesuburan tanah.

Menurut Subhan dan Sumarna (1994), pemberian mulsa organik akan memberikan suatu lingkungan pertumbuhan yang baik bagi tanaman karena dapat mengurangi evaporasi, mencegah penyinaran langsung sinar matahari yang berlebihan terhadap tanah serta kelembaban tanah dapat terjaga, sehingga tanaman dapat menyerap air dan unsur hara dengan baik. Sedangkan yang beperan dalam meningkatkan mikroorganisme tanah adalah bahan organik yang diberikan ke dalam tanah yaitu berupa BBA. Pada lahan percobaan, pengaplikasian BBA yang diberikan ke tanah tidak sama ditiap perlakuannya. Pada lahan dengan sistem OTI, BBA dicampur ke dalam tanah sedangkan pada lahan sistem TOT BBA hanya ditebar di atas permukaan tanah. Hal tersebut akan memberikan hasil yang berbeda terhadap nilai C-mik tanah.

Pada 9 BST tanaman tebu mulai menggugurkan daunnya sehingga daun-daun tersebut jatuh ke tanah dan terdekomposis, kemudian dimanfaatkan oleh mikroorganisme sebagai sumber energi yang baru. Sedangkan pada lahan dengan aplikasi mulsa bagas terjadi akumulasi sumber bahan organik yang tinggi sehingga terjadi penurunan C-mik tanah. Menurut Miura, et al. (2015), yang melakukan penelitian pada lahan yang sama dengan penelitian ini, penambahan mulsa bagas dan olah tanah pada perkebunan tebu di tahun pertama berpengaruh nyata, namun pada tahun ketiga tidak berpengaruh nyata terhadap komposisi dan jumah mikroba di dalam tanah. Hal tersebut dikarenakan mikroorganisme merubah komposisi dan fungsinya dalam menanggapi perlakuan aplikasi mulsa bagas. Sehingga perubahan mikroorganisme di dalam tanah tersebut mempengaruhi proses-proses penting di dalam tanah seperti penyerapan karbon.

Berdasarkan data penelitian (Tabel 4), C-organik tanah dan kadar air tanah tidak berkorelasi dengan Cmik tanah. Hal ini karena C-organik yang terkandung di dalam tanah masih rendah dan belum dapat memberikan pengaruh terhadap keberadaan mikroorganisme tanah. Kadar air tanah tidak berpengaruh nyata terhadap Cmik tanah. Hal ini diduga karena mikroorganisme memerlukan keadaan yang optimum untuk pertumbuhan hidupnya. Penerapan OTI mengakibatkan tanah terdegradasi sehingga kadar air tanahnya menurun. $\mathrm{pH}$ tanah dan suhu tanah berpengaruh nyata terhadap Cmik tanah. $\mathrm{pH}$ tanah berkorelasi negatif terhadap Cmik tanah, semakin tinggi $\mathrm{pH}$ tanah maka nilai $\mathrm{C}$-mik tanah akan semakin menurun.

Menurut hasil penelitian Ardi (2009) pada $\mathrm{pH}$ tanah berkisar 5,0-6,1 ditemukan adanya mikroorganisme di dalam tanah hal ini sejalan dengan Lay dalam Ardi (2009) bahwa ada beberapa mikroorganisme yang mampu hidup dengan baik pada tanah dengan keadaan $\mathrm{pH}$ masam salah satunya adalah fungi. Suhu tanah berkorelasi negatif terhadap C-mik tanah (Tabel 4). Hal ini berarti semakin tinggi suhu maka nilai C-mik tanah akan semakin menurun. Suhu yang optimum akan mendukung pertumbuhan mikroorganisme tanah. 


\section{KESIMPULAN}

Berdasarkan hasil penelitian ini dapat disimpulkan bahwa sistem olah tanah tidak berpengaruh nyata terhadap C-mik tanah pada pertanaman tebu tahun kelima. C-mik tanah pada perlakuan aplikasi mulsa bagas lebih tinggi dibandingkan dengan perlakuan tanpa mulsa bagas pada waktu pengamatan 0,3 dan $9 \mathrm{BST}$. Tidak terdapat interaksi antara perlakuan olah tanah dan aplikasi mulsa bagas terhadap C-mik pada pertanaman tebu tahun kelima.

\section{DAFTAR PUSTAKA}

Ardi, R. 2009. Kajian aktivitas mikroorganisme tanah pada berbagai kelerengan dan kedalaman hutan alam. Skripsi. Universitas Sumatra Utara. Medan.

Djajakirana, G. 2003. Metode-metode penetapan biomassa karbon mikroorganisme tanah secara langsung dan tidak langsung: kelemahan dan keunggulannya. Tanah dan Lingkungan. 5(1): 29-38.

Franzluebbers, A. J., F. M. Hons, dan D. A. Zuberrer. 1995. Soil organic carbon, microbial biomass, and mineralizable carbon and nitrogen in sorgum. Soil Sci. Soc. Am. J. 59: 460-466.

Hakim, N., M. Nyakpa, A.M.Lubis, S.G. Nugroho, M.A. Diha, G.B.Hong, dan H.H. Bailey. 1986. DasarDasar Ilmu tanah. Universitas Lampung. Bandar Lampung. $448 \mathrm{hlm}$.

Jenkinson, D.S. dan D.S. Powlson. 1976. The effect of biocidal treatments on metabolism in soil-V. fumigation with chloroform. Soil. Biol. Biochem. 8: 209-213.

Margarettha. 2004. Studi biologi tanah dalam penerapan beberapa teknik pengolahan tanah dan sistem pertanaman pada ultisol. Agronomi. 8(2): 117-120.

Miura, T., A. Niswati, I. G. Swibawa, S. Haryani, H. Gunito, M. Arai, K. Yamada, S. Shimano, N. Kaneko, dan K. Fujie. 2015. Shifts in the composition and potential functions of soil microbial communities responding to a notillage practice and bagasse mulching on a sugarcane plantation. Biol Fertil Soils. (51)8: 307-322.

Pratiwi, T. D. 2013. Pengaruh pengolahan tanah dan pemberian mulsa bagas terhadap kandungan biomassa karbon mikroorganisme tanah pada lahan pertanaman tebu tahun kedua. Skripsi. Universitas Lampung. Bandar Lampung.

PT Gunung Madu Plantations. 2009. Pengolahan Tanah. Available online at http://www. Gu- nungmadu.co.id., [31 Maret 2015].

Subhan dan A.Sumarna. 1994. Pengaruh Dosis Fosfat dan Mulsa terhadap Pertumbuhan Vegetasi dan Hasil Kubis (Brassica oleracea L.) Buletin Penelitian Hortikultura. 27(1): 1-11.

Utomo, M. 1995. Reorientasi Kebijakan Sistem Olah Tanah. Prosid. Sem. Nas-V. BDP-OTK, Bandar Lampung, hlm: 1-7.

Utomo, M. 2012.Tanpa Olah Tanah Teknologi Pengelolaan Pertanian Lahan Kering. Lembaga Penelitian Universitas Lampung. Bandar Lampung. $110 \mathrm{hlm}$. 